\title{
Dossiê
}

\begin{abstract}
Resumo
No cruzamento da psicologia individual, das relações familiares e sociais e do âmbito médico, os distúrbios das condutas alimentares oferecem um modelo dos determinantes que se desenvolvem preferencialmente no adolescente e em sujeitos femininos. Este artigo retoma as principais discussões sobre as condutas alimentares, articulando-as aos mecanismos neurobiológicos que detêm o risco de uma depressão melancólica. Uma hipótese central será evocada: a falha da função materna, de modo particular, no investimento do corpo autônomo, vivo e erótico da criança. Essa falha não favoreceria uma integração suficientemente boa do feminino no sujeito $e$ participaria do advento de uma organização sadomasoquista fixando-o a objetos infantis.

Descritores: distúrbio alimentar; adolescência; clivagem corpo-psique; falha da função materna; integração do feminino.
\end{abstract}

\section{A ADOLESCENTE \\ ANORÉXICA E \\ SUA FAMÍLIA: UMA \\ DESAFILIAÇÃO POR ABSTINÊNNCIA}

\author{
Maurice Corcos \\ Tradução: Inesita Machado
}

DOI: http://dxdoi.org/10.11606/issn.1981-1624.v20i1p27-42.

\section{Introdução: aspectos fenomenológicos e dados experimentais}

A

epidemiologia dos Transtornos do Comportamento Alimentar - TCA (particularmente a proporção entre os sexos - maciçamente feminina - e o fato de que estejam em questão essencialmente

- Psiquiatra. Professor e chefe do Departamento de Psiquiatria do Adolescente do Institut Mutualiste Montsouris (IMM), Docente da Universidade Paris Descartes, Paris, França. 
os meios favorecidos ou em vias de estabilidade onde o estatuto da mulher evoluiu de modo mais sensível) é suficientemente eloquente para que se possa considerar que a problemática dessas afecções esteja ligada, em grande parte, à problemática mais geral da feminilidade e à problemática da constituição da identidade de gênero psíquica e corporal na adolescência.

Este eixo será abordado particularmente com a proposta de hipóteses sobre a transmissão genealógica e transgeracional nesses distúrbios. Refletiremos essencialmente sobre os mecanismos de identificação que garantem essa transmissão e sobre seu papel na constituição das bases narcísicas do sujeito.

Atualmente existem muitos trabalhos experimentais sobre distúrbios das condutas alimentares que se referem a distúrbios na interação mãefilho ou nas interações familiares.

A teoria do apego permitiu o desenvolvimento de instrumentos de investigação dessas interações. Por meio dessa teoria, o grau de segurança do apego, bem como de seus aspectos qualitativos, pode ser avaliado. A grande maioria dos trabalhos recentes que utilizaram esses instrumentos mostrou uma incidência elevada do apego inseguro em sujeitos com distúrbios de condutas alimentares. A partir de Bowlby (1982) distinguem-se habitualmente duas formas de apego inseguro: o que evita ou é desapegado ou o ambivalente ou preocupado. Nos distúrbios das condutas alimentares, parecem existir diferenças entre pacientes anoréxicas e pacientes bulímicas: pacientes anoréxicas pertencem normalmente à categoria que evita ou é desapegado e as bulímicas à categoria ambivalente ou preocupado. Assim, pareceria que os distúrbios do apego possam constituir um fator de risco do advento de distúrbios alimentares e igualmente um fator de prognóstico. Todavia, alguns autores (Ward, Ramsay, \& Treasure, 2000; Ward, Ramsay, Turnbull, Benedettini, \& Treasure, 2000) ressaltaram a variabilidade da transmissão de uma criança a outra na mesma família. Pesquisas mais refinadas sobre aspectos específicos do apego são necessárias para dar maior precisão a seu papel etiológico, um trabalho que não realizaremos no âmbito desse artigo.

\section{Abordagem do funcionamento familiar: abordagem sistêmica}

Os terapeutas sistêmicos enfatizam os aspectos transgeracionais nas patologias do laço. Com o aporte da psicanálise, pode-se incluir na

28 Estilos clin., São Paulo, v. 20, n. 1, jan./abr. 2015, 27-42. 
adição a importância de uma temática pseudo-edípica, favorecida pela atitude contra-edípica ativa do pai, que participa no recurso ao tóxico para consumir uma fantasmática incestuosa. A coalisão pai-filha, tendo sido fissurada pelo desvelamento dos determinantes parentais, remete a paciente à uma identificação aditiva com o personagem materno. A clínica da adição modifica-se então com a fissura da fachada edípica que a sustentou por um tempo. É nessa flutuação secundária na fragilidade do laço paterno e no retorno da dissolução dos limites do eu na identificação ao objeto materno que um risco regressivo pode surgir como consequência dos determinantes narcísicos.

Os aspectos privilegiados nos trabalhos dos terapeutas sistêmicos são, por exemplo, a relação entre o sintoma individual e as transações grupais, a natureza dos fluxos de informações que circulam entre os membros da família em redes de expectativas recíprocas e seu efeito de domínio e de gerenciamento de uma homeostasia familiar pela intersecção do sintoma. Tais aspectos devem ser articulados às potencialidades de estruturação psíquica para a "criança designada" muito precocemente para um papel e uma função nesse sistema de interação, para a qual irão coabitar efeitos de investimento e de resistência mais ou menos inconscientes em face desses papéis e funções. Privilegiar esse ponto de vista permite conceber que rapidamente de uma situação passiva, 
a criança, e depois o adolescente conhecendo/nascendo ${ }^{1}$, tornar-se-á coautor em uma dinâmica familiar singular. Perseguidor-perseguido, a criança alternará momentos de repressão de suas emoções com momentos de descarga pulsional, talvez visando inicialmente ao domínio dos afetos do outro, potencialmente mortíferos para sua psique, em razão de seu funcionamento de domínio de tipo "tudo ou nada" e de sua ilegibilidade e imprevisibilidade. Antes de assumir seu estatuto designado, ela deve administrar seu caos interior. Se a criança dá, por exemplo, a impressão de responder ao ideal do eu materno e participar do trabalho de enfraquecimento da autoridade paterna, é seu corpo que deve se defender para proteger-se do domínio materno. Outro exemplo: se ela expressa por meio de seu comportamento sua percepção da desarmonia do casal parental e favorece a reaproximação do casal em torno de sua magreza, trata-se antes de tudo não da reivindicação de solicitude, mas de uma tentativa de compreender a proveniência de sua "falta em ser".

Enfim, se a separação de seu meio natural - que ocorre quando se institui o contrato de separação no caso de uma hospitalização - é tão dolorosa, é porque a monopolização compassiva em seu entorno (pais, irmãos, amigos, professores, médicos), tendo desaparecido perceptivelmente com a separação, corta-a do suporte ambiental que ela solicitou e orquestrou para fazer face à sua desorganização. Esse suporte mais ou menos pervertido constitui uma força e uma fonte de gozo da qual ela irá, a partir de então, sentir a falta.

Outro elemento que deve ser integrado em uma perspectiva genealógica dessa vez (e que deve ser distinto dos aspectos transgeracionais): não devemos conceber unicamente os problemas relacionais mãe-filha como referência a uma problemática psicanalítica clássica, seja ela edípica positiva ou negativa, isto é, de identificação ou de identidade (homossexualidade estruturante (Perrier, 1976): a filha, tornando-se mãe, "dota-se" de um materno que falhou em sua própria mãe. Para Fedida (2003), a questão genealógica não se resolve pelo estudo da psique dos pais e dos avós e nos efeitos de seus atos dirigidos à criança. A dimensão do mito não deve ser evitada. Esse autor entende que se deve deixar aberto o movimento regressivo na cura sem bloquear o pensamento regressivo do analista por plataformas conceituais com o objetivo de ter acesso à descoberta do que está encarnado no corpo de uma mulher e que está ligado ao seu enraizamento genealógico (o reino das mães, as figuras do destino; essa especificidade que faz com que o destino da humanidade passe pelas mulheres).

Enfim, não nos pareceu que este aporte bastante útil dos terapeutas sistêmicos enfatizasse suficientemente o lugar do corpo e da vivência física. As ausências de um dos membros da família e o fato de 
pacientes fazerem saídas brutais das entrevistas traduzem uma impossibilidade de permanecer nos "territórios familiares", nos quais surge certa excitação. Esta é redobrada pelo dispositivo da entrevista familiar e é pouco ou nada representável. Ela é, antes de qualquer coisa, vivida fisicamente, pois fora dos efeitos devidos a proximidade incestuosa, ela é muitas vezes gerada pelo fato de que no "puzそle familiar" reunido na entrevista faltam peças que, no entanto, existem e insistem ali no vazio. A metaforização dessa presença-ausência é difícil e deve ser encarnada fisicamente. Como disse uma paciente na saída de uma entrevista familiar, "a bulimia é um banquete em que como todas as partes; as dos que não vieram e que não virão comer".

Finalmente resta a questão dos limites da abordagem familiar (como a questão do momento da indicação) e dos riscos que ela incorre ao reificar a parte familiar do sintoma do adolescente em detrimento de seu aspecto de criação individual.

A entrevista familiar imobiliza o tempo (ou faz com que entrem em conluio diferentes tempos), o que gera excitação, mas continua a ser traumático enquanto o espaço em que ela se derrama permanecer improvável. Improvável porque os territórios psíquicos dos diferentes protagonistas se confundem. Em que momento o espaço familiar adquire na psicoterapia o status de um objeto terceiro? Em que momento as crianças poderão brincar pulsionalmente à sombra dos pais no espaço da entrevista familiar? Provavelmente quando estes estiverem suficientemente acalmados para que sua problemática não faça sombra às crianças.

Voltemos então a uma reflexão sobre a constituição singular do casal parental nos transtornos das condutas alimentares.

\section{Reflexões sobre o casal parental}

Uma paciente: "Estou entre o osso e a moela... um canal vazio".

Uma paciente: "Minha mãe não fala da dor; não falo de minha fome".

Uma paciente: "Estou no labirinto... Não vejo Ariadne.... Tenho a impressão de tê-la percebido... era uma bela mulher".

Uma paciente: "Com meu pai não é a mesma coisa. Há entre nós um espaço em que existo". 
Uma paciente: "Recuso a afeição de meu pai, pois não é a de minha mãe... meu pai quer que eu cresça... minha mãe quer que eu seja perfeita".

Uma paciente: "Meu erro foi ter separado meus pais, aí está toda minha espessura".

No desenvolvimento normal da infância, que volta a estar em jogo na adolescência, o amor materno constitutivo do narcisismo primário deve ser recalcado para que se crie uma ausência cuja distância por ela introduzida será fonte de construção identitária. Esse processo não se dá quando o recalque leva ao risco de perda de um suporte narcísico de identificação, ou, nos casos menos severos, em que a mudança de objeto edípico é problemática.

A fixação narcísica primária imposta pela mãe irá desde então pesar muito sobre a constituição do Supereu e do Ideal do Eu. Constitui-se uma clivagem de uma parte do eu que permanecerá identificada e dependente do funcionamento narcísico materno. $\mathrm{O}$ Eu vê-se confrontado ao Eu-Ideal, instância hipertrofiada e onipresente que se forma na criança por identificação narcísica com a mãe, com seus gestos, palavras, comportamentos. Uma paciente disse: "Sou o ideal de minha mãe... sou eu que modelo minha mãe, não é ela que quer transpor o que ela quis ser em minha personagem... mas ao mesmo tempo ela me idealizou completamente... Tudo o que faço é fantástico para ela". Qualquer solicitação objetal posterior, particularmente na adolescência, conduzirá a um retraimento da libido sobre posições narcísicas: uma redução do Eu ao Eu Ideal remetendo à fusão narcísica primária com o objeto. Qualquer frustração despertará essa regressão com suas angústias esquizoides.

Um ponto importante: o ideal do eu se estrutura no Édipo com o genitor do mesmo sexo. Para Freud (1914/1969), o ideal do eu narcísico formou-se a partir de grandes quantidades de libido essencialmente homossexual. Nas TCA, a relação mãe-filha em termos de afirmação narcísica passa pelo corpo; o ideal do eu buscado por meio da procura de sensações é um ideal do eu corporal; a construção identitária, mimética na infância, oponente na adolescência, passará pelo corpo. O feminino (corporal) do sujeito se constitui em função do laço materno, e mais precisamente do investimento do si somático da criança pela mãe (Corcos, 2010).

A partir de dois anos, mas principalmente na adolescência, é o pai proibidor (muito cedo na psique materna, em sua capacidade de devaneio, e depois em sua presença efetiva e em seus atos e não 
unicamente em linguagem) que vem constituir o recalque primário e permite ao sujeito escapar do narcisismo primário, a esta "maternidade-perpetuação" evocada por Michaux (1998). A angústia de castração limita a expansão narcísica do si mesmo alienado no narcisismo materno e permite a assunção do sujeito.

Pode-se pensar que isso ocorre mais cedo, desde as inter-relações precoces, se o pai estiver suficientemente presente na cabeça da mãe, permitindo exercer-se a censura do amante (após a fase de "loucura materna" em que a mãe se identifica com sua filha e antecipa suas necessidades, ela redescobre o pai). A partir de então a filha pode continuar a identificar-se com a mãe. Uma mãe que redescobre o mundo com seu cônjuge.

É nesse espaço aberto pela mãe, e depois pelo pai suficientemente diferenciador que o processo de filiação deverá se iniciar pela pluralidade e pela diferenciação das identificações possíveis. Em outros termos, percebe-se constantemente nas TCA que as dificuldades na dinâmica familiar não favorecem o deslocamento do ódio sádico oral e anal da mãe para o ódio edípico do pai. Pseudoedípico de fachada, onde a identificação com a mãe ao mesmo tempo fálica e castrada não é temperada com a identificação com um pai fálico castrador - limitador.

O papel dos pais nas TCA parece-nos estar intimamente ligado (de modo mais forte do que em outros lugares) ao lugar da mãe e à sua escolha de objeto amoroso e genitor face à sua própria problemática edípica. A criança não pode preencher um sem se opor ao outro. Constantemente, ela se apega ao mais frágil dos dois (a mãe), identifica-se em espelho com ela e participa da exclusão do pai. Um Édipo não mentalizado, não elaborado na mãe, deixa a filha em uma identificação com uma mãe pré-edípica e com sua sexualidade pré-genital tornando seu Édipo barrado acima (o acesso a um Édipo negativo e à problemática homossexual) e trancado abaixo (em razão das dimensões psicopatológicas paternas: problemática homossexual e atitude contra-edípica ativa).

Frequentemente considerado apagado, submisso, incapaz de ter autoridade, e até mesmo excluído da vida familiar, ele aparece como estando muito presente, com uma posição edípica maciça que rivaliza com a da mãe (esta o aceita parcialmente com ambivalência) e uma atitude mais ou menos manifestamente sedutora diante de sua filha. "Pai-urso" ou "Pai-mãe", sua identidade parece mal assegurada, suas identificações femininas sendo prevalentes: 
o que dá conta de sua dificuldade em encontrar a "distância correta" no momento da adolescência de sua filha, e sua facilidade em deslizar para um papel maternante em detrimento de uma função limitadora. A realidade da qualidade da relação enodada entre pai e filha encontra-se muitas vezes correlata à organização psicopatológica da anorexia ou da bulimia; ao pai contra-edípico corresponde um funcionamento mais histérico, mais associado a vômitos auto-provocados e a crises bulímicas (formas mistas); ao pai mais retraído e até mesmo perseguido em uma organização para-psicótica, corresponde um fundo mais depressivo e até mesmo esquizoide, conforme o lugar do pai na anorexia mental (Bochereau \& Agman,1994).

A questão do pai nas TCA é complicada pela imbricação de moções transgeracionais. A mãe muitas vezes "escolheu" o pai em função desses entraves e de sua problemática narcísica e edípica. Em alguns casos graves, o pai que apresenta uma dimensão homossexual mais ou menos recalcada também escolheu uma mulher singular pouco feminina e até mesmo fálica, e vê sua filha como um duplo feminino, ele mesmo vivendo como um filho de sua mulher. Esse olhar para sua filha, que se soma ao olhar materno que recusa qualquer feminilidade, tem uma incidência sobre o investimento corporal da filha. Assim, pode haver uma barragem no papel do pai em diferenciar filha e mãe, em permitir "à filha sair do amor de 
sua mãe e se 'filiar' a um pai" (Fedida, 2003). Os outros aportes paternos: constituição do ideal do eu - função simbólica com passagem dos valores da adolescência aos valores sociais - e saber do pai sobre psique e gozo materno são barrados se for a mãe "que faz a lei".

O pai também tem como função, de modo mais essencial, nomear a falha materna (a depressão materna, os entraves neuróticos...) ao mesmo tempo à criança e à sua mulher, permitindo, no espírito da criança, o deslocamento de uma imagem de mãe arcaica devoradora para a mãe edípica. Assim, o fracasso em inscrever a relação com o pai na ordem simbólica favoreceria a união devoradora com a mãe.

Há um apelo a um pai, um juiz, uma lei, um limite e um terapeuta homem na terapia bifocal que proibiria a morte, sendo uma saída para a morbidade da identificação narcísica com a mãe, e de separação da confusão homossexual. A convicção de seduzir ativamente o pai, não em um cenário histérico em que o pai é o sedutor, mas em uma inversão desse cenário (o corpo sexual da adolescente sedutora) seria problemática, sendo que o fantasma de ser sedutora diante de um pai é investido pela filha na medida de sua percepção da não satisfação materna.

\section{A terceira mulher}

Porém, impõe-se outro terceiro; a avó materna, que é para a criança o lugar de uma memória onde se encontra imaginariamente uma solução para o transtorno fascinante enterrado no espelho materno. Antes disso, os clínicos habituados aos TCA sabem da importância da mãe pré-edípica representada pela avó materna: educação precoce da criança razoavelmente longa pela avó e apego mantido; vivência insuportável pela menina na adolescência das semelhanças físicas e de caráter com sua avó; rivalidade da mãe em relação ao par menina-avó; descompensações das TCA nas meninas (ambivalência) por ocasião da morte da avó.

Citemos uma paciente: "Minha avó materna é uma grande doente, de quem eu não gosto nem um pouco, ainda que ela tenha me educado de 0 a 8 anos. Minha mãe estava sozinha e 
trabalhava até tarde... Posso dizer que conheço de certa forma a infância de minha mãe, sei o que ela viveu... Um universo muito fechado onde só havia lugar para as restrições."

Gostaríamos de enfatizar a frequência das preocupações corporais, senão alimentares, em um registro fóbico-obsessivo e caracterial nas avós maternas que se infiltram, como um "precursor sombrio", na relação com as mães de nossas pacientes. Assim, vemos constantemente e de modo espetacularmente caracterial (com pouca possibilidade de metaforização) que a anorexia da adolescente reflete para a mãe a imagem de sua própria mãe.

A mãe de uma paciente diz: "Ela tem o mesmo temperamento de minha mãe, ela me tiraniza como ela... Depois da morte de minha mãe, ela usou suas roupas durante muito tempo e tornou-se mirrada como ela."

Considerando os elementos projetivos, parece-nos que muitas vezes a adolescente solicita sua mãe no fantasma, em relação a um trabalho de elaboração de uma depressão muda resultante de conflito reprimido com sua mãe. Assim, um dos efeitos da "doença" da adolescente sobre as relações mãe-avó é certamente a reativação de um conflito antigo entre elas.

A rivalidade tão frequente das pacientes com TCA em relação aos irmãos menores seria apenas o reflexo de uma problemática edípica banal, ou deveria ser pensada como Édipo 
negativo ou invertido (filho da relação homossexual por identificação com a mãe pré-edípica)?

Evidentemente, nesse laço privilegiado, pensamos em um amor incestuoso partilhado, gerando um fantasma de filiação exclusiva na linhagem das mulheres, de acordo com Héritier (1994): "Podemos nos perguntar se essa aspiração à partenogênese não seria o veículo do desejo de imortalidade" (p. 10). Mas a dimensão homo (isto é, narcísica), mais do que sexual, parece prevalecer. Assim, como Racamier (1992), falaremos em incestual, mais do que em incestuoso. O termo incestual para esse autor tem uma dimensão transgeracional, pois supõe repetição do domínio narcísico sobre várias gerações. Ele não implica diretamente a sexualidade; a problemática é, antes disso, a de uma integração identitária correta. Mas muitas vezes o sexual está em primeiro plano na clínica para obstruir a ameaça identitária.

A tomada de consciência pelas pacientes em psicoterapia individual e familiar desses determinantes maternos no apego de suas mães por elas (contrapondo seu próprio apego por suas mães) tem um efeito dissipador de confusão e alívio. A fidelidade-lealdade exigida pelo contrato narcísico não é mais necessária e separar-se da mãe não significa mais traição e abandono. Uma paciente diz: "Fidelidade não era a palavra conveniente... tratava-se de lealdade... fidelidade significaria que eu sabia e concordava... é mais lealdade... porque eu era obrigada por meu nascimento”.

\section{O caminho para as mães}

Para concluir sobre o lugar, a função e o estatuto de transmissões inter e transgeracionais psíquicas, e também de vivências corporais, voltaremos à questão dos dois protagonistas essenciais na TCA (a mãe e a adolescente) e ao trabalho de investigação conjunta do significado dessa transmissão enigmática. A transmissão dos conteúdos psíquicos de um dos pais ao seu filho, em um processo de filiação, permite a identificação a esse último. A identificação é estruturante para um sujeito que consegue integrar os conteúdos psíquicos sem tantos atritos, quando esses são oferecidos de forma não imposta, fugindo à via da sedução massiva. A identificação pode ser alienadora se a transmissão for essencialmente narcísica ou enigmática e, 
portanto, fonte de captação do sujeito a seu objeto de adição. Podemos então pensar as relações mãe-filho a partir da relação do adicto com seu objeto de adição.

Poderíamos considerar um modo de transmissão por identificação patológica particularmente expressiva durante os tratamentos das TCA, enfatizando novamente a diferença de expressão clínica sintomática entre as mães (repressão) e as filhas (ação). O que na mãe é conteúdo na inibição e temperamento, na filha é ação corporal obstinada. O deslocamento possível na mãe de sua problemática narcísica sobre seu temperamento e modo relacional corresponde a externalização comportamental corporal do conflito na ação aditiva na filha.

Pontalis (1981) enfatiza essa passagem de testemunho da expressão do sofrimento psíquico:

O que na mãe eram devaneios inofensivos, pensamentos vagos, possíveis sem contorno, tornavam-se atos breves impulsivos na filha, apenas para ver o efeito produzido sobre os outros e o efeito que isso teria sobre ela: imprimindo sua marca sobre todos os que passariam ao seu alcance, forçando-a a reagir, ela saberia o que ela era. Tanto pior para os passantes, contanto que eles lhe servissem de revelador! (p.60)

A criança, "futura adolescente aditiva", parece ter se colado a um modelo de identificação com uma mãe caracterial (com uma dimensão anal prevalente incluindo-se algumas zonas de negação e de clivagem, particularmente da imagem do corpo, não simbolizadas e não elaboradas pela mãe) contra o qual ela não pode lutar eficazmente sem risco de uma descompensação materna (traição narcísica, frequência da depressão materna com a melhora psíquica da adolescente). Tomemos dois momentos clínicos:

Uma paciente fala da injunção de sua avó materna à sua mãe quando esta lhe revelou sua primeira relação sexual: Se você dormin com este aí, você pode dormir com todos os homens. Sua mãe irá desenvolver uma inibição sexual maior. A paciente (sua filha) associa então sobre seu comportamento aditivo alimentar: se eu como, se eu começo a comer, não posso mais parar. O paralelo com a avó-oráculo é evidente. O terapeuta fala então da ação corporal da paciente e de seu efeito de apagamento físico dos caracteres sexuais secundários na anorexia da filha, em relação à repressão neurótica do desejo na mãe.

Assim, os efeitos da transmissão transgeracional metabolizam-se de modo diferente por conta da absorção pela geração intermediária e pela avó oráculo. A adição da filha é, em parte, a herança da inibição materna. É o que veremos na continuação do diálogo, quando a paciente, após ser interrogada pelo terapeuta sobre seu desejo por homens (em ressonância com o desejo do terapeuta de curar a paciente, de "torna-la gorda"), responde: "isso me enoja, me faz vomitar." 
"O que você vomita?", ele retoma, subentendendo seu desejo ou então o desejo de alguma coisa em um homem.

"Algo em mim."

"Você pensa que assim irá emagrecer e não ser mais desejável (apetitosa) para um homem?"

"Penso que os homens têm um toque de perversão."

"Por continuarem a desejar essa imagem de morto?"

"Não, nada disso, por desejarem uma criança."

Em um contexto edípico, o que se inscreve na linhagem materna da avó para a filha é o impossível do feminino, da relação heterossexual, o nojo do corpo e sua destruição. Em um contexto mais narcísico, desenvolve-se uma insuficiência identitária psique-soma oculta por uma problemática neurótica. O que se inscreve na linhagem das mulheres é a "incerteza de um corpo" vivido sem qualidade.

Observemos que o sistema não é, entretanto, fechado, como ele pode ser na melancolia, pois a diferença sintomática (ação versus inibição) leva a um caminho perigoso. Assim, segundo Guyotat (1995), a passagem ao ato aditivo poderia ser interpretada, em sua forma mais extrema, como uma "libertação da filiação narcísica instituída ... uma passagem, através da filiação instituída, para a filiação do corpo a corpo, isto é, o inverso do nascimento: a destruição do corpo" (p. 179).

Essas rememorações levam à evocação da dimensão transgeracional operando nas condutas aditivas e à percepção de uma dimensão, nessas condutas de ruptura, de filiação corpo a corpo, pois ela impõe a vida em esquemas ou desejos parentais mortíferos, ou até mesmo não desejos, ambos sinônimos de ausência de investimento.

$\mathrm{Na}$ abordagem desses esquemas parentais seria preciso desenvolver a ideia de que estes são modelados sobre a filiação real ou imaginária dos pais. Tocamos aqui de modo mais profundo os aspectos transgeracionais da identificação com a busca imaginária de uma identidade, que se encontra em parte determinada por aquilo que é rejeitado na história dos pais e que restará por um tempo anestesiado (Ferenczi, 1932/1990) antes de ser utilizado na construção identitária.

Em outros termos, a personalidade se estrutura alienando-se em torno de uma rejeição, negação, forclusão, repressão ou de uma filiação parental imaginária construída à medida do vazio enigmático que se torna símbolo da filiação do sujeito e de sua inscrição na linhagem genealógica. O segredo ou o não-dito atrai o sujeito 
para um questionamento sobre a origem, a identidade e a filiação. É com o resto desse segredo que se desenvolvem todas as construções do sujeito. Todas essas construções são questionadas tão logo um evento levante o véu desse segredo. É o não dito que causa a indefinição do objeto materno para a criança, é essa "inclusão não viva" (Guyotat ,1995) que gera a disfunção mãe-filho desde as primeiras inter-relações.

Assim, desde muito cedo a criança parece "prisioneira" do fantasma do não-dito que seu objeto projeta: ela percebe aí certa tonalidade dramática impossível de decifrar, enredando seu próprio desenvolvimento. Essa prisão, mantida pelo sujeito até que ele se torne o co-carcereiro juntamente com seu objeto para estabelecer conhecimento, não seria uma simples prisão mental. Ela implicaria mais profundamente fantasmas de um mesmo corpo.

ANOREXIC TEENAGERS AND THEIR FAMILIES: A DIS AFFILIATION BY ABSTINENCE

\begin{abstract}
At the intersection between of individual psychology, family and social relationships and the medical field, eating disorders offer a model of the determinants that develop preferably in teenagers and female subjects. This article resumes the main discussions on eating behaviors, articulating them to the neurobiological mechanisms that offer risk of melancholic depression. A central bypothesis will be raised: the failure of the maternal function, and, particularly, in the investment in the autonomous, living and erotic body of the children. This failure would not favor a sufficiently good integration of the feminine in the subject and would participate in the advent of a sadomasochistic organization fastening it to child objects.
\end{abstract}

Index terms: eating disorder; adolescence; body-psyche cleavage; failure of maternal function; feminine integration.

\title{
LA ADOLESCENTE ANORÉXICA Y SU FAMILIA: LA DESAFILIACIÓN POR ABSTINENCIA
}

\section{Resumen}

En el cruce de la psicología individual, de las relaciones familiares y sociales y del campo de la medicina, los trastornos de las conductas alimentarias ofrecen un modelo de los determinantes que se desarrollan preferentemente en las adolescentes y mujeres adultas. Este articulo retomó los principales debates acerca de las conductas alimentarias, articulándolos con los mecanismos neurobiológicos que guardan el riesgo de depresión melancólica, teniendo la bipótesis central de que es falla de la función materna y, particularmente, de la inversión en el cuerpo autónomo, vivo y erótico de la niña. Esa falla no favorecería una buena integración suficiente del femenino en el sujeto y participaría del advenimiento de una organización sadomasoquista fijandole a objetos infantiles.

Palabras clave: trastornos de la alimentación; adolescencia; escisión cuerpo-psique; falla de la función materna; integración del femenino.

40 Estilos clin., São Paulo, v. 20, n. 1, jan./abr. 2015, 27-42. 


\section{REFERÊNCIAS}

Atger, F., Corcos, M., Perdereau, F., \& Jeammet, P. (2001). Attachement et conduites addictives. Annales de médecine interne, 3 (152), 1567-1572.

Bochereau, D., \& Agman, G. (1994). Rencontre avec des pères d'adolescentes anorexiques. Neuropsychiatrie de l'enfance et de l'adolescence, 42 (6), 233-239.

Bowlby J. (1982). Attachment and Loss (2a. ed.). London: United Kingdom: Pimlico.

Ciocca, A., Bria, P., \& Risio, S. de. (Orgs.) (1998). Psychotherapeutic issues on eating disorders: models, methods and results. Rome: Italy: Società Editrice Universo.

Chabert, C. (1998). Les voies intérieures. In $59^{\circ}$ congrès des psychanalystes de langue française, in enjeux de la passivité, bulletin de la société psychanalytique de Paris, 51 (9-65). Paris, France.

Chassler, L. (1997). Understanding anorexia nervosa and bulimia nervosa from an attachment perspective. Clinical Social Work Journal, 4 (25), 407-423.

Corcos, M. (2010). Le corps absent: approche psychosomatique des troubles de conduites alimentaires. [S.1.]: Dunod.

Fairburn, C., Welch, S., Doll, H., Davies, B., \& O'Connor, M. (1997). Risk factors for bulimia nervosa: a community-based case-control study. Arch Gen Psychiatry, 54 (6), 509-516.

Fedida, P. (2003). L'arrière mère et le destin de la féminité. Psychanalyse à l'Université, 18 (5), 195-212.

Ferenczi, S. (1990). Psychanalyse IV: Euvres complètes 1927-1933. [S.1.]: Payot. (Trabalho original publicado em 1932)

Freud, S. (1969). Pour introduire le narcissisme. In La Vie sexuelle (pp. 81-105). Paris: PUF. (Trabalho original publicado em 1914)

Guyotat, J. (1995). Filiation et puerpéralité, logiques du lien: Entre psychanalyse et biomédecine, Paris: PUF.
Heritier, F. (1994). De l'inceste. Paris: France: Odile Jacob.

Hodes, M., Timimi, S., \& Robinson P. (1997). Children of mothers with eating disorders: a preliminary study. European Eating Disorders Review, 5 (1), 11-24.

Humphrey, L. (1987). Comparison of bulimic-anorexic and nondistressed families using structural analysis of social behavior. Journal of the American Academy of Child \& Adolescent Psychiatry, 2 (26), 248-255.

Israel, L. (1994). Le désir à l'oeil. [S.1.]: Les Cahiers d'Arcanes.

Jacobi, C., Agras, W. S., \& Hammer, L. (2001). Predicting children's reported eating disturbances at 8 years of age. Journal of the American Academy of Child \& Adolescent Psychiatry, 40 (3), 364-372.

Jeammet, P. (1989). Psychopathologie des troubles des conduites alimentaires à l'adolescence: valeur heuristique du concept de dépendance. Confrontations Psychiatriques, 31 (22), 179-202.

Michaux, H. (1998). Entre centre et absence. In Euvres complètes, Paris: France: Gallimard.

O'Kearney, R. (1996). Attachment disruption in anorexia nervosa and bulimia nervosa: a review of theory and empirical research. The international journal of eating disorders, 20 (2), 115-27.

Perrier, F. (1976). La Chaussée d'Antin. Paris: Bibliothèque Idée.

Pontalis, J. (1981). Non, deux fois non. In L'emprise: Nouvelle Revue de Psychanalyse, [S.1.]: Gallimard.

Racamier, P.-C. (1992). Le génie des origines - psychanalyse et psychoses. Paris: France: Payot.

Valery, P. (1996), La Jeune Parque et poèmes en prose. Paris: France: Gallimard.

Ward, A., Ramsay, R., \& Treasure, J. (2000a). Attachment research in eating disorders. The British Journal of Medical Psychology, 73 (1), 35-51. doi: 10.1348/000711200160282

Ward,A., RamsayR., Turnbull, S., Benedettini,M., \& Treasure J. (2000b). Attachment patterns 
in eating disorders: past in the present. The International Journal of Eating Disorders, 28 (4), 370-376. doi:10.1002/1098-108X(200012)28:4<370::AID-EAT4>3.0.CO;2-P

\section{NOTA}

1 - N.do T.: co-naissant na língua francesa remete a duas significaçóes "conhecimento" e "nascimento com".

mcorcos@hotmail.com

42, Boulevard Jourdan 75014 - Paris - França.

Recebido em dezembro/2014. Aceito em fevereiro/2015.

42 Estilos clin., São Paulo, v. 20, n. 1, jan./abr. 2015, 27-42. 